\title{
22 An investigation into the archaeological application of carbon stable isotope analysis used to establish crop water availability: solutions and ways forward
}

\author{
Helen R. Stokes, Gundula Müldner and Emma Jenkins
}

\section{ABSTRACT}

Carbon stable isotope analysis of charred cereal remains is a relatively new method employed by archaeological scientists to investigate ancient climate and irrigation regimes. The aim of this study was to assess the effect of environmental variables on carbon isotope

discrimination $(\Delta)$ in multiple environments to develop the technique and its archaeological application, using crops grown at three experimental stations in Jordan. There are two key results: (1) as expected, there was a strong positive relationship between water availability and $\Delta ;$ (2) site, not water input, was the most important factor in determining $\Delta$. Future work should concentrate on establishing ways of correcting $\Delta$ for the influence of site specific environmental variables and on assessing how well carbon isotope discrimination values are preserved within the archaeological record.

\subsection{INTRODUCTION}

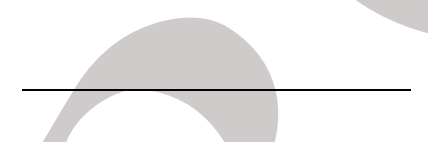

Carbon stable isotope analysis of archaeological cereals is a relatively new approach for the investigation of ancient irrigation systems (Araus and Buxo, 1993; Araus et al., 1997b; Ferrio et al., 2005; Araus et al., 2007; Riehl et al., 2008). The approach relies on the basic principle that plants under water stress discriminate less against the 'heavier' carbon- $13\left({ }^{13} \mathrm{C}\right)$ isotope than plants whose water requirements are fully met (Farquhar and Richards, 1984; Farquhar et al., 1989). As a consequence, the tissues of water-stressed plants contain more ${ }^{13} \mathrm{C}$ than those which have received sufficient water through rainfall or irrigation. Although this general principle regarding water availability and carbon isotope discrimination $(\Delta)$ is fully established within modern plant sciences, using carbon stable isotope analysis of plant tissues to investigate archaeological questions has its own specific challenges. A central question concerns the extent to which environmental variables other than water stress affect ${ }^{13} \mathrm{C}$ discrimination in plants and whether these effects can be sufficiently accounted for in past environments. Addressing this issue was one of the key aims of the Water, Life and Civilisation project's experimental crop growing programme in Jordan (Mithen et al., 2008). This chapter reports on the first results of this investigation, by first discussing how carbon stable isotope analysis of cereal remains is currently used within archaeology and then presenting the outcomes of a pilot study into the effect of water stress on carbon stable isotope signatures under different environmental conditions using wheat from three crop growing stations in Jordan.

\subsection{PRINCIPLES OF THE METHOD}

Isotopes are atoms of the same element which have different atomic masses. Carbon has three naturally occurring isotopes: carbon-12 $\left({ }^{12} \mathrm{C}\right)$, which makes up $~ 99 \%$ of carbon atoms, carbon-13 $\left({ }^{13} \mathrm{C}\right)$ and carbon- $14\left({ }^{14} \mathrm{C}\right)$. Unlike ${ }^{14} \mathrm{C}$ (radiocarbon), ${ }^{12} \mathrm{C}$ and ${ }^{13} \mathrm{C}$ isotopes are stable and not subject to radioactive decay. The ratio of ${ }^{12} \mathrm{C}$ to ${ }^{13} \mathrm{C}$ (expressed as ${ }^{13} \mathrm{C} /{ }^{12} \mathrm{C}$ or $\delta^{13} \mathrm{C}$ ) is widely used within environmental sciences to understand natural pathways and food webs within ecosystems (see Rundel et al., 1987; Lajtha and Michener, 1994; Dawson and Siegwolf, 2007).

During photosynthesis, plants discriminate against the 'heavier ${ }^{13} \mathrm{C}$ isotope in favour of the 'lighter' ${ }^{12} \mathrm{C}$ isotope. In plants using the $\mathrm{C}_{3}$ or Calvin-Benson photosynthetic pathway (most land plants and major cultigens) this results in plant tissues containing a far lower proportion of ${ }^{13} \mathrm{C}$ compared with ${ }^{12} \mathrm{C}$ isotopes than the atmosphere (Lajtha and Michener, 1994). The size of the difference between atmospheric $\delta^{13} \mathrm{C}$ and the isotopic composition of plant tissues (carbon isotope discrimination or $\Delta$ ) depends on a number of different factors. 
Farquhar and colleagues (Farquhar and Richards, 1984; Farquhar et al., 1989; Ehleringer et al., 1993) were, however, the first to establish a relationship between water status and carbon isotope discrimination in plants. The basic principle they observed was that, as a result of stomatal closure and associated changes in intercellular partial pressure, water-stressed plants discriminate less against ${ }^{13} \mathrm{C}$ than plants which have their water needs met (see Ehleringer, 1989; Farquhar et al., 1989; Ferrio et al., 2003). Put very simply, as water stress increases, the difference $(\Delta)$ between the $\delta^{13} \mathrm{C}$ of atmospheric $\mathrm{CO}_{2}$ and plant tissue decreases. The value of $\Delta$ can therefore act as a record of water availability during plant growth. Small $\Delta$ values should reflect poor water availability and high $\Delta$ values greater water availability. This relationship between water stress and $\Delta$ is being used by archaeological scientists to track changes in climate and instances of agricultural irrigation in prehistory.

\subsection{APPLICATIONS IN ARCHAEOLOGY}

\subsubsection{Carbon stable isotope analysis for reconstructing climate change}

Climate change has been identified as an important factor driving social change in early societies during the Holocene (e.g. Dalfes et al., 1997; Rosen, 2007). As carbon stable isotope data from $C_{3}$ plants reflect moisture conditions, they can be expected to track changes in climate over time. In the first applications of this methodology to charred cereal remains from archaeological sites, Araus and colleagues (Araus and Buxo, 1993; Araus et al., 1997a) compared $\Delta$ values for wheat and barley kernels from southeastern and northeastern Spain dating from the Neolithic to the Iron Age (7,000-2,200 BP). They concluded that the southeast had been consistently drier than the northeast and that, although climate was generally wetter than today, there was a trend towards more arid conditions throughout the periods studied (see also Araus et al., 2003). More recently, Riehl et al. $(2008,2009)$ demonstrated that stable carbon isotopes in plants record broad-spectrum environmental changes. The main focus of Riehl et al. (2009) was to assess the reliability of pedogenic carbonates from southeastern Turkey as palaeoenvironmental indicators. To achieve this they compared the carbonate data with three local palaeoenvironmental records including archaeological seed assemblages, $\Delta^{13} \mathrm{C}$ evidence from plant remains and the predictions of macrophysical climatic models (MCM). Seven early Bronze Age to Classical (5,400-2,000 cal BP) sites from northern Mesopotamia and the northern Levant were considered along with previously published data, giving a total sample size of 200 barley grains. Riehl et al. (2009) found that there was a good general correlation between $\Delta{ }^{13} \mathrm{C}$ values and other palaeoclimate indicators, particularly in the identification of a temporary increase in moisture levels during the mid-Holocene followed by a decrease thereafter. However, the authors are quick to point out that considerable further research is still needed to improve the chronology of these proxy data in order to produce a more accurate picture of climate change within the northern Fertile Crescent.

\subsubsection{Carbon stable isotope analysis for reconstructing irrigation practices}

Water management systems are at the centre of the debate surrounding the emergence of complex societies in arid regions of the world (e.g. Scarborough, 2003). Unfortunately, they are often difficult to detect archaeologically (see Mithen et al., 2008). A reliable method for establishing whether artificial crop irrigation existed at an ancient settlement would therefore be invaluable. Initial investigations, especially by Araus and his group (Araus and Buxo, 1993; Araus et al., 1997a, 1997b, 1999) suggest that plant stable carbon isotope analysis has great potential in this respect, as it should, theoretically, be possible to infer from the carbon stable isotope composition of crops whether they received more water than was 'naturally' available, and therefore whether a system of artificial irrigation was in place. In order for this approach to be viable, it is first essential to distinguish between the effects on carbon isotope discrimination caused by irrigation and those of climate fluctuations. Secondly, it is necessary to establish how much water was available through natural means (precipitation) or rather, what $\Delta$ values would be expected in crops that were grown at the same site, i.e. under the same environmental and climatic conditions, yet without any artificial irrigation. As a possible solution to these issues, researchers have started contrasting carbon isotope discrimination data for a number of different plant species from the same archaeological site. The aim is to identify differences in $\Delta$ between these crops which could then be explained in terms of differences in irrigation and crop management techniques (Araus et al., 1997b; Ferrio et al., 2005; Riehl et al., 2008). In relation to this, Ferrio et al. (2005) proposed comparing isotope data from major food crops with the remains of non-cultivated plants such as trees or with cultigens which are relatively well adapted to arid conditions and are therefore unlikely to have received any irrigation (see also Ferrio et al., 2005, 2006). Following this suggestion, Riehl et al. (2008) used $\Delta$ values for barley as baseline data for non-irrigated crops. They combined these data with the results of climate modelling to infer that irrigation was practised at some of the investigated sites. While the strategies employed to detect irrigation through carbon stable isotope signals of plants are therefore relatively sophisticated, all researchers concede that the trends observed in their datasets may well be explained by differences in the growing cycles or water use efficiency of individual species rather than 
by any water management strategies employed by humans (Ferrio et al., 2005; Riehl et al., 2008).

\subsubsection{The importance of modern reference data}

Modern reference data from plants grown under known climatic and hydrological conditions are essential for the correct interpretation of carbon stable isotope values obtained from archaeological specimens. Apart from establishing the importance of environmental parameters other than water availability on the carbon isotope discrimination of plants (see discussion below), these modern analogues are used to provide typical $\Delta$ values for rain-fed and irrigated plants in a given geographical region. These can then be compared with archaeological samples from the same area. The majority of work establishing modern reference data has been undertaken by Araus and colleagues (Araus and Buxo, 1993; Araus et al., 1997b; Ferrio et al., 2005) and has centred on the Mediterranean, especially Spain. They employed the reference values from modern crops mainly in two ways: as baseline data for relative statements about past climate conditions ('wetter/drier than today') (Araus et al., 1997a; Ferrio et al., 2003 , 2005), or for establishing relationships between the $\Delta$ of different types of crops grown under the same environmental conditions. As we have seen above, such data are essential for identifying irrigated crops by comparison with other, probably non-irrigated, plant species from the same site (Araus et al., 1997b, 1999; Ferrio et al., 2005). Araus and colleagues (Araus et al., 1997b, 1999; Ferrio et al., 2003) also used modern $\Delta$ values from crops grown under a variety of known watering regimes to formulate non-linear regression equations for calculating total water input from $\Delta$ values.

\subsection{OTHER ENVIRONMENTAL PARAMETERS AFFECTING $\Delta$}

The importance of water availability, and especially total water input during grain filling, for $\Delta$ is not in doubt. It is a wellestablished principle in modern plant science and emerged, for example, as the most important environmental parameter when Araus et al. (2003) tested samples of 25 genotypes of durum wheat from 12 experimental fields in different regions of Spain.

Nevertheless, there are a number of other environmental factors which contribute to the overall plant carbon isotope signature. Modern studies of carbon isotope discrimination in crops are primarily aimed at refining the use of $\Delta$ as a selection criterion for crop improvement (e.g. Monneveux et al., 2006). They have the benefit of large sample sizes and are, in consequence, affected by sources of small-scale variation in $\Delta$. In contrast, when studying archaeological materials sample sizes are restricted by what is available and therefore typically very small. At the same time,

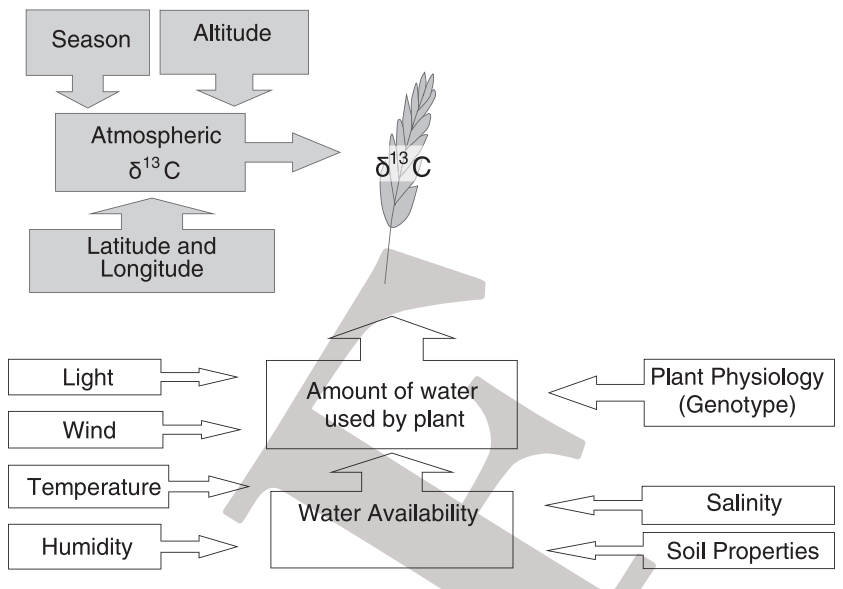

Figure 22.1. Flowchart illustrating the different environmental parameters determining the carbon stable isotope composition $\left(\delta^{13} \mathrm{C}\right)$ of $\mathrm{C}_{3}$ plants (for references, see text).

palaeo-data describing environmental parameters such as rainfall, temperature or moisture conditions are usually sporadic. In these cases, it is pertinent to ask whether the effect on $\Delta$ of environmental variables other than water availability is large enough to influence the interpretation of carbon isotope datasets. The main variables in question are discussed below.

\subsubsection{Evapotranspiration and local growing conditions}

While water input, whether from precipitation or artificial irrigation, is usually the most important factor influencing $\Delta$, concurrent water loss through evaporation (from the soil) and transpiration (through the plant) is also a key variable for determining the water status of plants. It therefore also has a known effect on $\Delta$. The rate of transpiration is the result of complex interplay between plant physiology and transpiration efficiency as well as light intensity, air movement, temperature and humidity (see Figure 22.1 and Allen et al., 1998; see also Farquhar et al., 1989; Condon et al., 1992; Ferrio et al., 2003; Monneveux et al., 2006). The presence of dense tree cover can have a particularly strong effect on the isotopic composition of plant tissues, probably as the combined result of reduced light levels and $\mathrm{CO}_{2}$ 'recycling' under the canopy (van der Merwe and Medina, 1991; Heaton, 1999; Ferrio et al., 2003). The difference between $\delta^{13} \mathrm{C}$ values of a plant in the canopy and one in the understorey can be as much as $3-4 \%$ (Heaton, 1999). The relative position of the plant within the overall environment is therefore very important when interpreting carbon stable isotope data obtained from plants.

The nature of soil is also crucial to understanding differences in plant $\Delta$ values. Apart from evaporation, other properties such as soil depth, water holding capacity, salinity, soil resistance and nitrogen content can either limit the water available to crops or affect photosynthesis rates in other ways (see Masle and Farquhar, 1988; Farquhar et al., 1989; Condon et al., 1992; Shangguan et al., 2000; 
Shaheen and Hood-Nowotny, 2005; Cabrera-Bosquet et al., 2007). The variable nature of soil properties means that they can change considerably within a relatively small area, affecting noticeable intra- and interspecies differences in plant stable isotope composition within the same habitat (Tieszen, 1991; Heaton, 1999).

\subsubsection{Variations in atmospheric $\delta^{13} \mathrm{C}$ and $\mathrm{CO}_{2}$ concentrations through time}

Throughout the Holocene there have been fluctuations in the concentration and the ${ }^{13} \mathrm{C}$ content of atmospheric $\mathrm{CO}_{2}$. Both result in variations in the $\delta^{13} \mathrm{C}$ of plant tissues even where other environmental factors are constant (Heaton, 1999; Ferrio et al., 2003). It is therefore necessary to correct for any changes in atmospheric composition before samples from different time periods can be compared. This is normally done through the use of ice core data which provide information on the isotopic composition and concentration of atmospheric $\mathrm{CO}_{2}$ for the period in question. These data are then used as a basis to calculate $\Delta$ for archaeological samples (see Ferrio et al., 2005; Araus et al., 2007; Riehl et al., 2008).

\subsubsection{Geographical variables}

Two key geographical variables are altitude and latitude, which affect plant $\Delta$ probably as a result of changes in atmospheric partial pressure and variations in temperature (Korner et al., 1991). Korner et al. (1988) studied the effect of altitude on carbon isotope discrimination of $\mathrm{C}_{3}$ plants across major mountainous regions and found that $\Delta$ was reduced in magnitude by 2 $3 \%$ per $1,000 \mathrm{~m}$ altitude on a community level and by $1.2 \%$ within species. After surveying a number of studies, Heaton (1999) reported an average decrease in $\Delta$ of between 0.5 to $1.5 \%$ for every $1,000 \mathrm{~m}$ of elevation. In a subsequent study, Korner et al. (1991) also established that latitude influences $\Delta$ values. Plants at higher-latitude sites (Arctic and sub-Arctic lowland) typically exhibit lower $\Delta$ values and therefore discriminate less against ${ }^{13} \mathrm{C}$ than vegetation at tropical sites at similar altitudes. These results demonstrate that care must be taken when conducting inter-site comparisons or even pooling samples from different locations, especially in regions with marked differences in altitudes. For larger settlements which may have been sustained from a sizeable hinterland, the question must also be asked whether all crops were grown locally.

\subsection{DEVELOPING A MODERN REFERENCE DATASET FOR ARCHAEOLOGICAL STUDIES IN JORDAN}

The above discussions highlight the importance of establishing good regional reference values for any given area before conducting carbon stable isotope analysis of charred plant remains.
They also raise the question of whether we really can sufficiently control variation at a local level to allow meaningful comparison between sites from different time-periods. Few modern crop growing experiments are designed with archaeological samples in mind, and, for want of better alternatives, modern samples are often assembled from a number of sites which differ not only in water availability but also in other environmental parameters such as altitude (see, for example, Araus and Buxo, 1993; Araus et al., 1997b, 1999).

The primary aim of this chapter is to explore the sensitivity of carbon stable isotopes in cereal kernels to water stress in different environments but where water input should be the only considerable variable at a site level. A land race of durum wheat (Triticum durum) was chosen for analysis as it is one of the earliest known cultivates within the Near East. In undertaking this study we are seeking to assess the validity of comparing datasets from different sites, even from within a small geographical area, with the aim of establishing differences in water management strategies. At the same time, modern reference values for carbon isotope discrimination of wheat grown in this region will also be established. These are essential before further isotope studies can explore the antiquity of active water management in crop production in one of the key areas for early agriculture.

\subsubsection{Experimental crop growing sites}

The Water, Life and Civilisation project's crop growing experiments in Jordan are described in detail by Jenkins et al. (this volume, Chapters 21 and 23) and Mithen et al. (2008). In brief, native land races of durum wheat were grown over three consecutive years (2005-2008) at three crop growing stations on the Jordanian plateau (Khirbet as Samra and Ramtha) and in the Jordan Valley (Deir 'Alla) (Figure 22.2). At each site the cultivation area was divided into five $5 \mathrm{~m} \times$ $5 \mathrm{~m}$ irrigation plots, varying from $0 \%$ irrigation (rainwater only) to $40 \%$ (second and third year only), $80 \%, 100 \%$ and $120 \%$ of the plants' optimum water requirements. These were estimated on a weekly basis using readings from Class A Evaporation Pans. The environmental conditions at each site were monitored closely, including minimum and maximum daily temperature, rainfall, evaporation and relative humidity.

\subsubsection{Sampling strategy}

In order to explore the relationship between $\Delta$ values, water availability and the environment, wheat kernels from each of the five irrigation regimes and all three years of cultivation were 


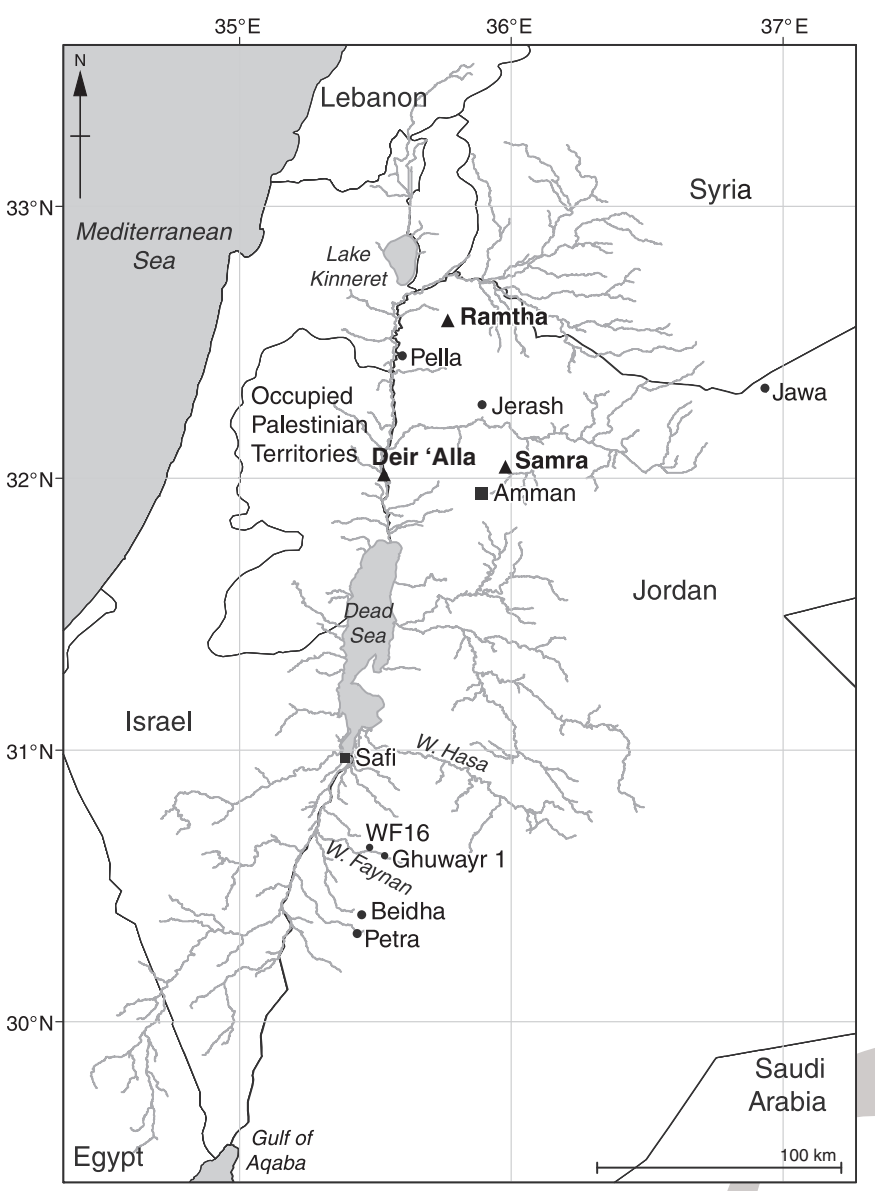

Figure 22.2. Location of crop growing stations in Jordan used in the WLC experiments (map reproduced from Fig. 1 of Mithen et al. 2008). Khirbet as Samra N $32^{\circ} 08^{\prime}$, E $36^{\circ} 09^{\prime}, 564 \mathrm{~m}$ asl, Ramtha $\mathrm{N} 32^{\circ} 33^{\prime}$, E $32^{\circ} 36^{\prime}, 510 \mathrm{~m}$ asl and Deir 'Alla N $32^{\circ} 13^{\prime}$, E $35^{\circ} 37^{\prime}$, $234 \mathrm{~m}$ bsl. Altitudes were obtained from the Google Earth database and were checked against OS maps (Ordnance Survey 1949a and $\mathrm{b}$ and 1950).

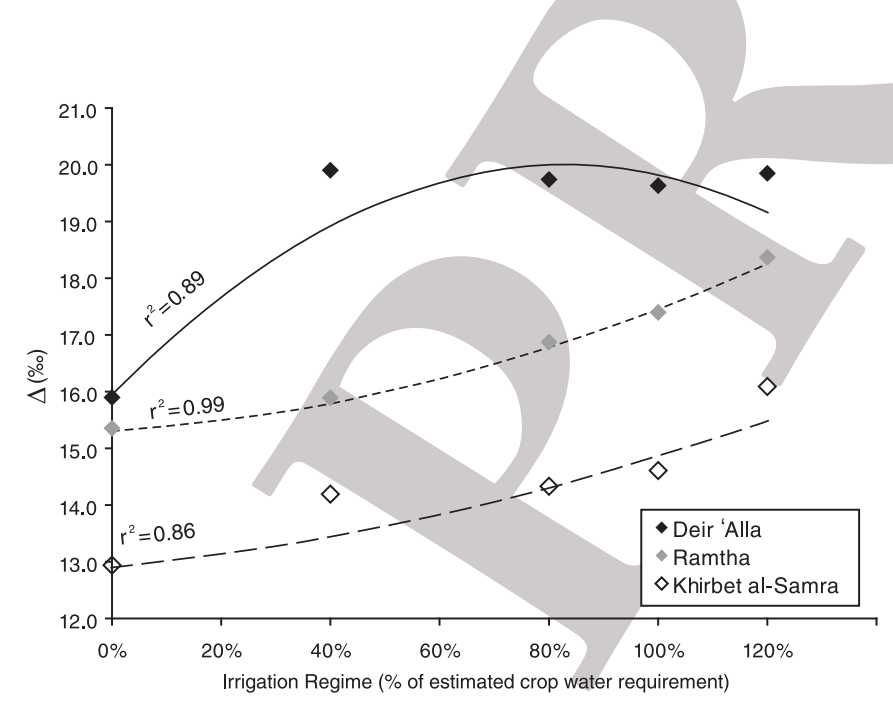

Figure 22.3. Graph showing mean $\Delta(\%)$ values for each irrigation regime at the three sites with trendlines fitted by polynomial regression. sampled at each of the three sites. This strategy was also meant to make it possible to assess the quantitative effect of varying water input on plant $\Delta$ values.

\subsubsection{Processing and methods.}

Each sample consisted of 10 wheat kernels from one water regime and year of cultivation. All grains were washed in deionised water, frozen for at least 24 hours, freeze-dried for 48 hours and then homogenised using a pestle and mortar. After exploring measurement reproducibility with multiple replicates of the same sample, it was found that analysing samples in duplicates provided sufficient precision. All analyses were conducted by continuous-flow isotope ratio mass spectrometry (analytical error $\pm 0.1 \%(1 \sigma)$ ). Values for $\delta^{13} \mathrm{C}$ (relative to VPDB) were converted into positive $\Delta$ values using the formula:

$$
\Delta=\frac{\delta_{\text {air }}-\delta_{\text {plant }}}{1+\delta_{\text {plant }} \div 1000}
$$

\subsubsection{Statistical analysis}

In order to establish the relationships between the major variables (water regime and site) and $\Delta$ values statistically, regression analysis was conducted using the GenStat ${ }^{\mathbb{R}}$ software package. The statistical analysis was conducted on $\delta^{13} \mathrm{C}$ values before they were converted into $\Delta$ values.

\subsection{RESULTS}

The results are displayed in Figure 22.3 and Table 22.1. For the purpose of this chapter, we have averaged data from different years of cultivation. As expected, there were strong positive relationships between $\Delta$ and water availability at each of the three sites (Figure 22.3). More unusually, however, the curves follow different trajectories. While the one for Deir 'Alla levels out at $40 \%$ water availability, $\Delta$ values at Ramtha and Khirbet as Samra are still increasing at $120 \%$. Importantly, there also appears to be an offset in $\Delta$ between the sites which is relatively consistent through the different watering regimes. Although there is some variation, the average difference between sites is about $2.1 \%$, with Deir 'Alla exhibiting the highest values (overall mean $18.9 \pm 1.7 \%$ o $1 \sigma)$, followed by Ramtha $(16.8 \pm 1.6 \%$ o) and finally Khirbet as Samra, where $\Delta$ are smallest $(14.7 \pm 1.0 \%)$

We applied a General Linear Model using the GenStat ${ }^{\circledR}$ program in order to test the importance of the two major variables, site and irrigation regime, for $\Delta$. The analysis confirmed the visual impression from Figure 22.3 that the relationships of $\Delta$ with both of these variables were statistically significant (accumulated ANOVA, $p<0.001$ in both cases). 
Table 22.1 Table showing mean $\Delta$ values in \%.

\begin{tabular}{|c|c|c|c|c|c|c|c|c|c|}
\hline \multirow[t]{2}{*}{ Irrigation regime } & \multicolumn{3}{|c|}{ Deir ‘Alla (234 m bsl) } & \multicolumn{3}{|c|}{ Ramtha (523 m asl) } & \multicolumn{3}{|c|}{ Khirbet as Samra (564 m asl) } \\
\hline & $\Delta$ (mean) & $1 \sigma$ & $n$ (years) & $\Delta$ (mean) & $1 \sigma$ & $n$ (years) & $\Delta$ (mean) & $1 \sigma$ & $n$ (years) \\
\hline $0 \%$ & 15.9 & 0.5 & 3 & 15.4 & 1.2 & 3 & 12.9 & - & 1 \\
\hline $40 \%$ & 19.9 & 0.5 & 2 & 15.9 & 0.9 & 2 & 14.2 & 0.6 & 2 \\
\hline $80 \%$ & 19.7 & 0.3 & 3 & 16.9 & 2.1 & 3 & 14.3 & 0.3 & 3 \\
\hline $100 \%$ & 19.6 & 0.2 & 3 & 17.4 & 0.9 & 3 & 14.6 & 0.2 & 3 \\
\hline $120 \%$ & 19.8 & 0.4 & 3 & 18.4 & 0.7 & 3 & 16.1 & 0.1 & 3 \\
\hline Overall mean & 18.9 & 1.7 & 14 & 16.8 & 1.6 & 14 & 14.7 & 1.0 & 12 \\
\hline
\end{tabular}

Values shown are average of up to three years of cultivation and overall average of all available samples, and standard deviation $(1 \sigma)$ for each site across all irrigation regimes. Some years did not produce sufficient cereal crop for analysis because of the dry conditions and attack by birds (see Mithen et al., 2008).

\subsection{DISCUSSION}

\subsubsection{Water availability and $\Delta$}

Wheat kernels from all three sites show the expected positive relationship with water availability, with an increase in $\Delta$ of $\sim 3 \%$ o (Ramtha, Khirbet as Samra) to 4\% (Deir 'Alla) from the lowest to the highest value. The trends exhibited are not uniform. The curve for Deir 'Alla levels out at $40 \%$ of the calculated crop water requirement, indicating that water is no longer the limiting factor to photosynthesis. Conversely, $\Delta$ values at Ramtha and Khirbet as Samra are still increasing at $120 \%$, suggesting that the plants' water requirements have not yet been fully met.

The easiest explanation for these different trends is that estimates of optimal water requirements were not fully accurate, possibly because these were calculated on a weekly basis but not taking into account precipitation and humidity patterns of previous weeks and months which might still have affected water availability during grain filling. Deir "Alla is situated in the Jordan Valley and, from Figure 22.3 which shows $\Delta$ values levelling out at $40 \%$ water input, more water was available here than either at Khirbet as Samra or Ramtha. Detailed analysis of all environmental parameters is still ongoing. However, for now it is suggested that the differences between sites can be explained by differences in soil water holding capacity, surface runoff or local climate which could have produced much wetter conditions at Deir 'Alla. It is possible that similar local parameters explain the continuing water stress evident at Ramtha and especially Khirbet as Samra, the most arid of the three sites. It is worth mentioning here that preliminary results suggest significant interannual variation in crop response to irrigation regime at Ramtha, and that continuing water stress may have affected the plants only in the second year of cultivation, but skewed the overall mean values (as expressed in the high standard deviation in comparison with other sites, see Table 22.1). However, further analyses are necessary to verify this.

\subsubsection{Site-specific variables}

As Figure 22.3 illustrates, although the relationship of $\Delta$ with water availability is highly significant, location also has a very considerable effect on the magnitude of carbon isotope discrimination. Only some of these differences can be easily explained by the relatively large differences in altitude between Deir 'Alla (234 $\mathrm{m}$ below sea level), Ramtha (523 m asl) and Khirbet as Samra (564 $\mathrm{m}$ asl). As stated earlier, a difference in altitude has been found to decrease $\Delta$ by $0.5-1.5 \%$ with each $1,000 \mathrm{~m}$ of elevation (Heaton, 1999). Even the difference of almost $800 \mathrm{~m}$ between Deir "Alla and Khirbet as Samra could therefore only account for about a quarter of the $\sim 4 \%$ offset observed between average $\Delta$ values from the two sites. It does not explain the $\sim 2 \%$ o difference in mean $\Delta$ values between Khirbet as Samra and Ramtha which are almost at the same altitude. Other site-specific factors which are not as easily controlled in prehistoric samples therefore need to be considered.

In order to guard the crops from bird attack it was necessary to cover the fields at Deir "Alla and Ramtha with protective netting for part of the year. This may have resulted in increased humidity and may also have introduced a 'canopy effect' (see above), both possibly leading to higher calculated $\Delta$ values for the analysed plants, although the magnitude of this effect is difficult to quantify with the environmental data obtained. Other likely causes of variation are differences in rainfall patterns, soil properties or transpiration rates. Which, if any, of these factors was the most important will have to be determined by detailed analysis of the environmental data collected.

\subsection{CONCLUSIONS}

The results presented here highlight the importance of site-specific factors for the carbon stable isotope composition of cereal kernels. This observation is neither surprising nor new, given the 
multitude of parameters that impact on carbon isotope discrimination in plants. Nevertheless, it is important to emphasise that the variation observed in our study, between plants grown at different sites but with nominally the same water availability and in a relatively small geographical area, is as great as, and sometimes significantly larger than, differences which have been considered meaningful in inter-site comparisons of archaeological plant data (see Araus et al., 1997b; Ferrio et al., 2005; Riehl et al., 2008). While some of the causes for variation, such as differences in altitude, can be relatively easily accounted for, even for prehistoric sites (although it is not always made explicit in publications whether their effects are actually corrected for), others, such as soil conditions and rainfall patterns, are much more elusive for the past. Even carefully modelled values can only ever be approximations (see, for example, Riehl et al., 2008), and care should therefore be taken to avoid over-interpreting relatively small differences in calculated $\Delta$ values, even where sites are from the same geographical area.

Stable isotope analysis of plant remains has the makings of a powerful tool for the investigation of past crop husbandry practices. However, future research must centre on exploring new ways of establishing site-specific baselines, of assessing the magnitude of normal background variation ('noise'), and of investigating in greater detail than before if and when the isotopic composition of plant tissues is changed through taphonomic processes and burial in the ground. Only if these issues are resolved can the potential of the method be fully realised. The ongoing larger project, of which this pilot study has been only the first step, aims to make a significant contribution to addressing these open questions. Further work will systematically seek to assess and characterise the nature of the relationship between carbon stable isotope values and environmental parameters, not only in wheat but also in barley and sorghum. In addition to carbon stable isotopes, nitrogen isotopes and their response to different environments will also be analysed and complemented by the outcomes of charring and burial experiments which will address the issue of alteration of the stable isotope signal through taphonomic processes. Combined, these results will enable us to interpret data from archaeological plant remains with greater confidence and to maximise the information that can be gleaned from them, in order to significantly improve our understanding of water management strategies in the past.

\section{REFERENCES}

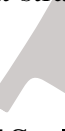

Allen, R. G., L. S. Pereira, D. Raes and M. Smith (1998) Crop Evapotranspiration - Guidelines for Computing Crop Water Requirements. FAO Irrigation and drainage papers 56. Rome: Food and Agriculture Organisation of the United Nations.

Araus, J. L. and R. Buxo (1993) Changes in carbon isotope discrimination in grain cereals from the North-West Mediterranean basin during the past seven millennia. Australian Journal of Plant Physiology 20: $117-128$.

Araus, J. L., A. Febrero, R. Buxo et al. (1997a) Changes in carbon isotope discrimination in grain cereals from different regions of the western Mediterranean Basin during the past seven millennia. Palaeoenvironmental evidence of a differential change in aridity during the late Holocene. Global Change Biology 3: 107-118.

Araus, J. L., A. Febrero, R. Buxo et al. (1997b) Identification of ancient irrigation practices based on the carbon isotope discrimination of plant seeds: a case study from the south-east Iberian Peninsula. Journal of Archaeological Science 24: 729-740.

Araus, J. L., A. Febrero, M. Catala et al. (1999) Crop water availability in early agriculture: evidence from carbon isotope discrimination of seeds from a tenth millennium BP site on the Euphrates. Global Change Biology 5: $201-212$.

Araus, J. L., J. P. Ferrio, R. Buxo and J. Voltas (2007) The historical perspective of dryland agriculture: lessons learned from 10,000 years of wheat cultivation. Journal of Experimental Botany 58: 131-145.

Araus, J. L., D. Villegas, N. Aparicio et al. (2003) Environmental factors determining carbon isotope discrimination and yield in durum wheat under Mediterranean conditions. Crop Science 43: 170-180.

Cabrera-Bosquet, L., G. Molero, J. Bort, S. Nogues and J. L. Araus (2007) The combined effect of constant water deficit and nitrogen supply on WUE, NUE and Delta C-13 in durum wheat potted plants. Annals of Applied Biology 151: 277-289.

Condon, A. G., R. A. Richards and G. D. Farquhar (1992) The effect of variation in soil water availability, vapour pressure deficit and nitrogen nutrition on carbon isotope discrimination in wheat. Australian Journal of Agricultural Research 43: 935-947.

Dalfes, H. N., G. Kukla and H. Weiss, eds. (1997) Third Millennium BC Climate Change and Old World Collapse. Berlin and Heidelberg: Springer. Dawson, T. E. and R. T. W. Siegwolf, eds. (2007) Stable Isotopes as Indicators of Ecological Change. London, Amsterdam, Oxford, Burlington \& San Diego: Academic Press.

Ehleringer, J. R. (1989) Carbon isotope ratios and physiological processes in arid land plants. In Stable Isotopes in Ecological Research, ed. P. W. Rundel, J. R. Ehleringer and K. A. Nagy. Heidelberg: Springer.

Ehleringer, J. R., J. K. Hall and F. D. Farquhar, eds. (1993) Stable Isotopes and Plant Carbon-Water Relations. San Diego and London: Academic Press.

Farquhar, G. D., J. R. Ehleringer and K. T. Hubick (1989) Carbon isotope discrimination and photosynthesis. Annual Review of Plant Physiology and Plant Molecular Biology 40: 503-537.

Farquhar, G. D. and R. A. Richards (1984) Isotopic composition of plant carbon correlates with water-use efficiency of wheat genotypes. Australian Journal of Plant Physiology 11: 539-552.

Ferrio, J. P., N. Alonso, J. B. Lopez, J. L. Araus and J. Voltas (2006) Carbon isotope composition of fossil charcoal reveals aridity changes in the NW Mediterranean Basin. Global Change Biology 12: 1253-1266.

Ferrio, J. P., J. L. Araus, R. Buxo, J. Voltas and J. Bort (2005) Water management practices and climate in ancient agriculture: inferences from the stable isotope composition of archaeobotanical remains. Vegetation History and Archaeobotany 14: 510-517.

Ferrio, J. P., J. Voltas and J. L. Araus (2003) Use of carbon isotope composition in monitoring environmental changes. Management of Environmental Quality 14: 82-98.

Heaton, T. H. E. (1999) Spatial, species, and temporal variations in the C-13/ C-12 ratios of C-3 plants: implications for palaeodiet studies. Journal of Archaeological Science 26: 637-649.

Korner, C., G. D. Farquhar and Z. Roksandic (1988) A global survey of carbon isotope discrimination in plant from high altitude. Oecologia 74: 623-632.

Korner, C., G. D. Farquhar and S. C. Wong (1991) Carbon isotope discrimination by plants follows latitudinal and altitudinal trends. Oecologia 88: $30-40$.

Lajtha, K. and H. Michener, eds. (1994) Stable Isotopes in Ecology and Environmental Science. Oxford: Blackwell Scientific Publications.

Masle, J. and G. D. Farquhar (1988) Effects of soil strength on the relation of water-use efficiency and growth on carbon isotope discrimination in wheat seedlings. Plant Physiology 86: 32-38.

Mithen, S., E. Jenkins, K. Jamjoum et al. (2008) Experimental crop growing in Jordan to develop methodology for the identification of ancient crop irrigation. World Archaeology 40: 7-25. 
Monneveux, P., D. Rekika, E. Acevedo and O. Merah (2006) Effect of drought on leaf gas exchange, carbon isotope discrimination, transpiration efficiency and productivity in field grown durum wheat genotypes. Plant Science 170: $867-872$.

Riehl, S., R. Bryson and K. Pustovoytov (2008) Changing growing conditions for crops during the Near Eastern Bronze Age (3000-1200 BC): the stable carbon isotope evidence. Journal of Archaeological Science 35: 1011-1022.

Riehl, S., K. E. Pustovoytov, S. Hotchkiss and R. A. Bryson (2009) Loca Holocene environmental indicators in Upper Mesopotamia: pedogenic carbonate record vs. archaeobotanical data and archaeoclimatological models. Quaternary International 209: 154-162.

Rosen, A. (2007) Civilizing Climate: Social Responses to Climate Change in the Ancient Near East. Plymouth: AltaMira Press.

Rundel, P. W., J. R. Ehleringer and K. A. Nagy, eds. (1987) Stable Isotopes in Ecological Research. Heidelberg: Springer.
Scarborough, V. L. (2003) The Flow of Power: Ancient Water Systems and Landscapes. Santa Fe, NM: SAR Press.

Shaheen, R. and R. C. Hood-Nowotny (2005) Effect of drought and salinity on carbon isotope discrimination in wheat cultivars. Plant Science 168: $901-909$.

Shangguan, Z. P., M. A. Shao and J. Dyckmans (2000) Nitrogen nutrition and water stress effects on leaf photosynthetic gas exchange and water use efficiency in winter wheat. Environmental and Experimental Botany 44: 141-149.

Tieszen, L. L. (1991) Natural variation in carbon isotope values of plants implications for archaeology, ecology and paleoecology. Journal of Archaeological Science 18: 227-248.

van der Merwe, N. J. and E. Medina (1991) The canopy effect, carbon isotope ratios and foodwebs in Amazonia. Journal of Archaeological Science 18: $249-259$. 